\title{
HPV16 E6 and E7 Upregulate Interferon-Induced Antiviral Response Genes ISG15 and IFIT1 in Human Trophoblast Cells
}

\author{
Lea M. M. Ambühl ${ }^{1}$, Annemarie B. Villadsen ${ }^{1}$, Ulrik Baandrup ${ }^{1}$, Karen Dybkær ${ }^{2}$ \\ and Suzette Sørensen ${ }^{1, *}$ \\ 1 Center for Clinical Research, North Denmark Regional Hospital/Department of Clinical Medicine, \\ Aalborg University, 9800 Hjørring, Denmark; 1.ambuhl@rn.dk (L.M.M.A.); annemarie.j@rn.dk (A.B.V.); \\ utb@rn.dk (U.B.) \\ 2 Department of Hematology, Aalborg University Hospital/Department of Clinical Medicine, \\ Aalborg University, 9000 Aalborg, Denmark; k.dybkaer@rn.dk \\ * Correspondence: suzette.soerensen@rn.dk; Tel.: +45-4023-4378
}

Received: 14 July 2017; Accepted: 31 August 2017; Published: 3 September 2017

\begin{abstract}
Human papillomavirus (HPV) is suggested to infect trophoblasts in the placenta, and HPV infections are reported to be more prevalent in pregnancies with adverse outcomes. Results are however controversial, and studies investigating the molecular consequences of placental HPV infections are lacking. We studied HPV DNA localization in the placenta in cases of spontaneous abortion/spontaneous preterm delivery as well as in elective abortion/normal full-term delivery. Using in vitro assays, we investigated downstream effects of HPV16 E6 and E7 expression in trophoblast cells at the gene expression level in order to gain increased biological insight into the interaction between HPV and the cellular host. Fluorescent in situ hybridization (FISH), combined with fluorescent immunohistochemistry (FIHC) to target the trophoblast marker CK7 clearly showed, that HPV DNA resides within syncytiotrophoblast cells in the placenta. In vitro HPV16 E6 and E7-transfected trophoblasts were analyzed by RNA sequencing, and results were validated by reverse transcription real time polymerase chain reaction (RT-qPCR) for selected genes in cell lines, as well as in patient material. We show that HPV16 E6 and E7 upregulate interferon-induced antiviral response genes ISG15 and IFIT1 in a human trophoblast cell line two-days post-transfection. This is a response that is not observed when assessing the gene expression levels of the same genes in HPV16-positive placenta samples. Investigations on viral activity find that HPV16 E6 and E7 are not transcribed in patients, possibly suggesting that HPV16 syncytiotrophoblast infection may be latent. We conclude that HPV localizes to syncytiotrophoblast cells of the placenta, and that active expression of HPV16 E6 and E7 induce an immediate interferon-induced antiviral response in trophoblast cells, which is not present in HPV-positive placenta samples, suggesting latent infection.
\end{abstract}

Keywords: human papillomavirus; trophoblast cell; placenta; interferon; antiviral response

\section{Introduction}

Human papillomavirus (HPV) is a small DNA virus known to cause genital warts and cervical cancer [1]. HPV is described as an exclusively keratinocyte-specific virus [2]. Nevertheless, HPV DNA has been detected in placenta [3-5], amniotic fluid [6,7], umbilical cord blood [8] and fetal membranes [9]. Placental HPV infection has been reported to be involved in spontaneous abortion, spontaneous preterm delivery and placental abnormalities [3,4]. Furthermore, it has been suggested that trophoblasts are the predominant target of HPV in the placenta [10], possibly causing abnormal placentation $[4,11,12]$. 
HPV E6 and E7 viral proteins are known to be the major transforming proteins in oncogenic HPV [13]. In epithelial cells, HPV E7 binds to the retinoblastoma protein $\mathrm{pRb}$, thereby deregulating the cell cycle, while HPV E6 binds to the tumor suppressor p53 and targets p53 for degradation [14]. This combination allows HPV to override cell cycle checkpoints and to replicate its DNA in non-cycling cells. In vitro studies investigating effects of HPV E6 and E7 on trophoblast cells show that HPV genes mimic their effects in keratinocytes [15]. Physiological changes observed upon HPV infection of trophoblast cells include highly defective endometrial cell recognition, cellular death and induction of a malignant phenotype [12]. Moreover, HPV has been shown to complete its life cycle in various trophoblast cell lines [11,12]. The decrease in trophoblast-endometrial cell adhesion caused by introduction of HPV E6 and E7 may influence the initial step of embryo implantation and suggests potential for abnormal placentation or gestational expulsion of the early embryo [4,12]. However, a convincing role for HPV infection in connection to pregnancy outcome, at the molecular level, as well as effects of HPV on gene expression of trophoblast cells still need to be demonstrated.

HPV prevalence in pregnant women varies widely and has been reported to depend on study design, tested tissue types, and geographical location of populations analyzed, as well as on used HPV detection methods [16]. Several studies suggest that HPV infection may be linked to spontaneous abortion, spontaneous preterm delivery and placental abnormalities [3,4,17], whereas others are unable to detect HPV in investigated material [18]. In a study performed by our group, HPV prevalence was not significantly different in placental tissue obtained from spontaneous abortions/spontaneous preterm deliveries compared to elective abortions/normal full-term deliveries (Ambühl et al. 2017 [19]). We were previously able to localize HPV DNA in specific placental cells using chromogen in situ hybridization (CISH) and an effect of HPV DNA in placental cells cannot be omitted. Therefore, this study aimed to investigate the cellular target of HPV by co-localization studies and to study downstream effects of HPV transfection in placental trophoblast cells at the gene expression level.

\section{Results}

\subsection{HPV Localizes in Syncytiotrophoblast Cells of the Placenta}

We have previously shown (Ambühl et al. 2017 [19]) using chromogen in situ hybridization (CISH), that HPV DNA appears to be localized to trophoblast cells in placental tissue. To confirm this, we investigated the specific placental cell type infected by HPV by fluorescent co-localization studies enabling a more profound examination of HPV signals in combination with a specific cell marker. HPV DNA localization was determined in placental tissue slides by double staining, combining fluorescent in situ hybridization (FISH) with a fluorescent immunohistochemistry (FIHC) reaction using DNA probes targeting E6/E7 and/or L1 HPV genes, and an antibody against trophoblast cells (CK7). HPV DNA was clearly observed to be localized in syncytiotrophoblast cells (Figure 1). 

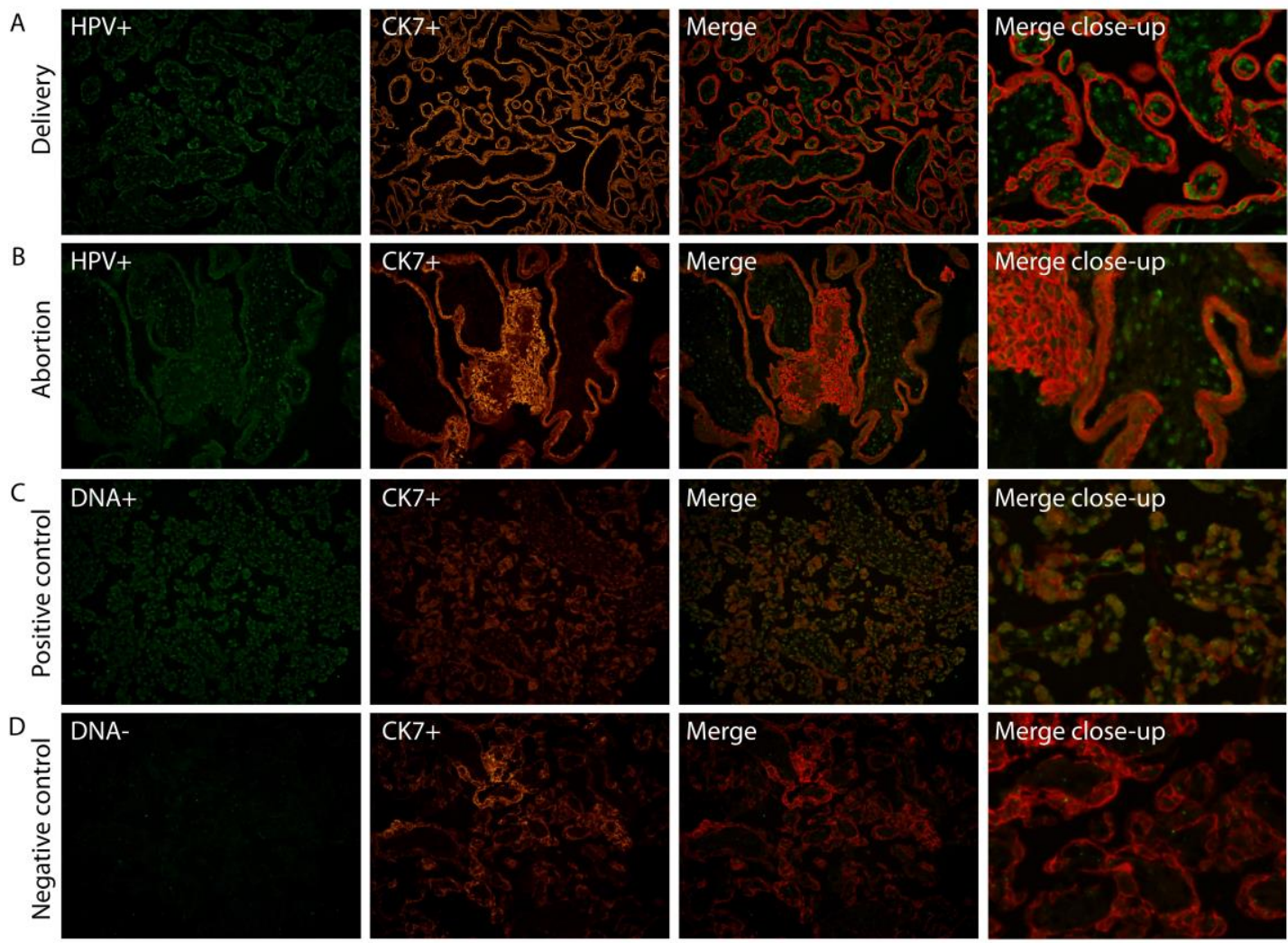

Figure 1. Human papillomavirus (HPV) targets syncytiotrophoblast cells. Combination of HPV-FISH and trophoblast cell FIHC. A representative example of both a normal full-term placenta (A) and aborted placental tissue (B) is included. HPV signals (HPV+) are in green, trophoblast cell marker $(\mathrm{CK} 7+)$ in red. A positive control including the $\mathrm{DNA}(+)$ probe $(\mathrm{C})$ and negative control using the DNA(-) probe (D) was used on a control placenta. Magnification: 20×. The merge close-up shows a representative section enlarged $300 \times$. FISH: fluorescent in situ hybridization; FIHC: fluorescent immunohistochemistry; CK7: trophoblast cell marker.

\subsection{Gene Expression of JAR Cells is Affected by HPV16 E6 and E7 Expression}

Localization of HPV DNA in syncytiotrophoblast cells indicates that HPV may play a biological role in placental function. Therefore, we studied the cellular effects of HPV16 E6 and E7 expression in a trophoblast cell line. We transfected JAR cells (a human choriocarcinoma cell line) with HPV16 E6 and E7-expressing plasmids, both separately and in combination. Using RNA sequencing, transcriptomes of JAR cells transfected with the empty construct were compared to those transfected with HPV genes two-days post-transfection. We found 25 significantly differentially expressed genes (DEGs); 15 genes were upregulated and 10 downregulated (Table 1). The genes that were differentially expressed varied depending on which HPV genes were transfected, and only two genes were found to be differentially expressed in all three transfection experiments (Figure 2). Most DEGs were only detected in one of the transfection conditions and HPV16 E7 appeared to have the greatest impact on the trophoblast transcriptome (Figure 2). Sequencing data were validated for selected genes by reverse transcription real time polymerase chain reaction (RT-qPCR) (for RT-qPCR data see Additional file 2) on transfected JAR cells (Table 2). Altered expression for all tested genes, except for one, was confirmed. Interestingly, two interferon-induced antiviral response genes ISG15 and IFIT1 were upregulated after transfection with HPV16 E6 and E7 (Table 2). 
Table 1. Differentially expressed genes after RNA sequencing (BGI).

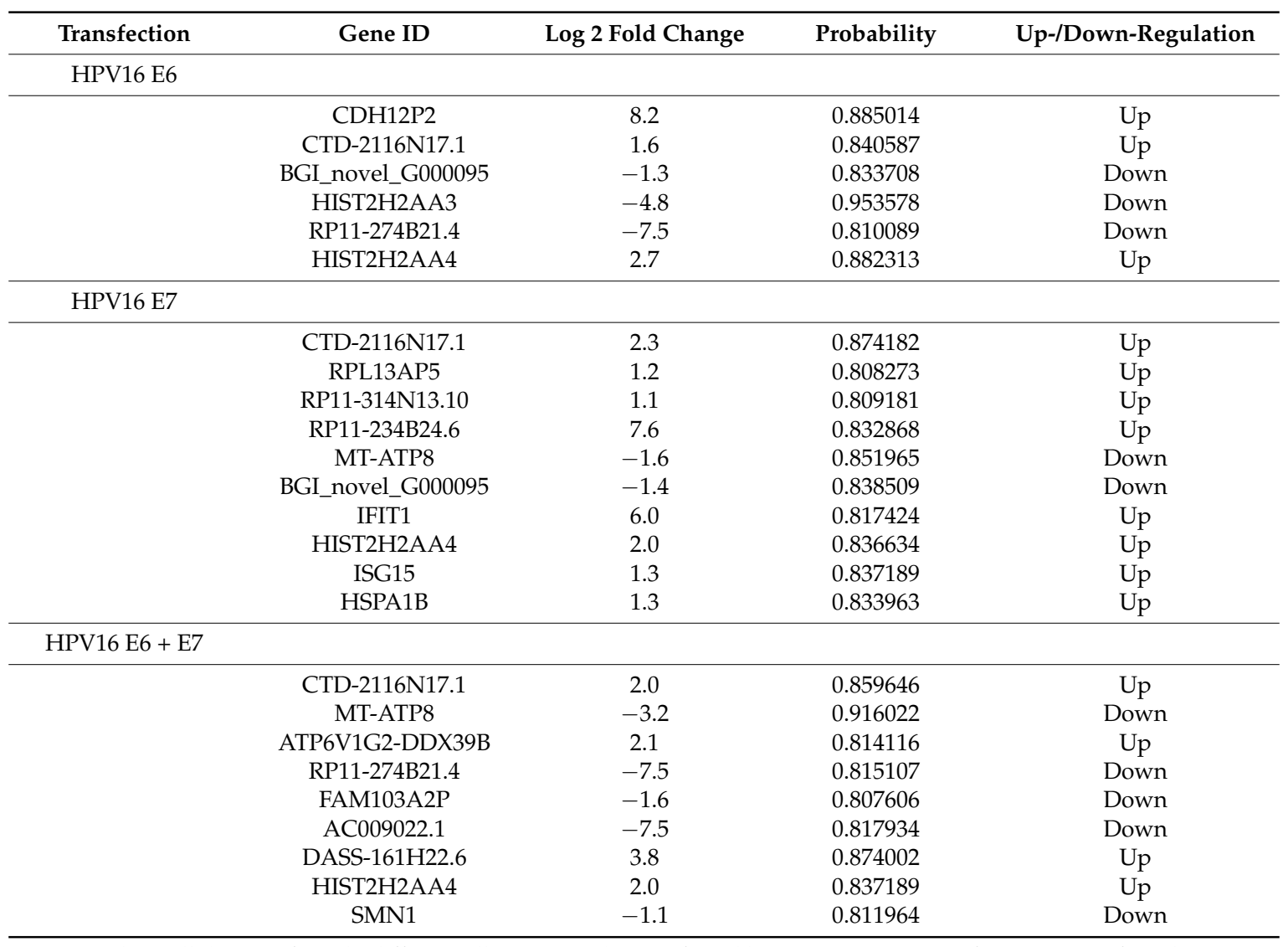

Listed are all the significantly differentially expressed genes found by RNA sequencing of HPV16-transfected JAR cells. Total RNA from transfections in triplicates were sequenced and grouped for comparative analysis using the noisy distribution model NOISeq described by Tarazona et al. 2011 [20]. Cutoff values chosen were the following: a probability $q=0.8$ and a minimum of 2 -fold change compared to the reference transfection using the empty plasmid pcDNA3.1.

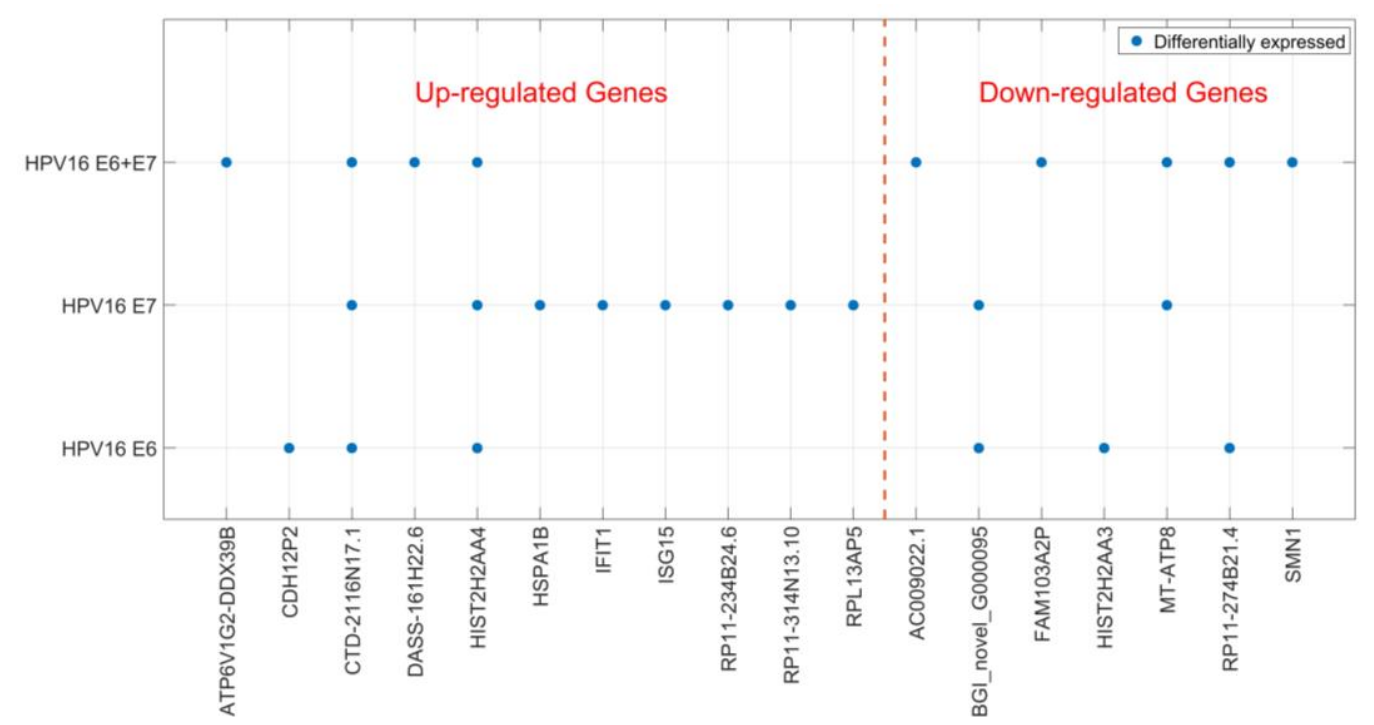

Figure 2. Differentially expressed genes after HPV16 E6- and E7-transfection. Significantly differentially expressed genes (DEGs) after HPV16 E6- and E7-transfection of trophoblast cells are shown depending on the transfected HPV genes. DEGs are divided into up- and down-regulated genes. 
Table 2. Validation in HPV16-transfected JAR cells.

\begin{tabular}{|c|c|c|c|c|}
\hline Gene ID & Transfection & $\Delta \Delta \mathrm{Ct}$ & $\begin{array}{l}\text { Fold-Change } \\
\quad\left(2^{-\Delta \Delta C t}\right)\end{array}$ & Validation \\
\hline IFIT1 & $\begin{array}{c}\text { HPV16 E6 } \\
\text { HPV16 E7 } \\
\text { HPV16 E6 + E7 }\end{array}$ & $\begin{array}{l}-3.38 \\
-3.72 \\
-2.17\end{array}$ & $\begin{array}{c}10.41 \\
13.18 \\
4.5\end{array}$ & $\begin{array}{l}\text { Up-regulation } \\
\text { confirmed }\end{array}$ \\
\hline ISG15 & $\begin{array}{c}\text { HPV16 E6 } \\
\text { HPV16 E7 } \\
\text { HPV16 E6 + E7 }\end{array}$ & $\begin{array}{l}-0.75 \\
-0.97 \\
-0.2\end{array}$ & $\begin{array}{l}1.68 \\
1.96 \\
1.15\end{array}$ & $\begin{array}{l}\text { Up-regulation } \\
\text { confirmed }\end{array}$ \\
\hline HSPA1B & $\begin{array}{c}\text { HPV16 E6 } \\
\text { HPV16 E7 } \\
\text { HPV16 E6 + E7 }\end{array}$ & $\begin{array}{l}-0.48 \\
-1.21 \\
-0.58\end{array}$ & $\begin{array}{l}1.39 \\
2.31 \\
1.49\end{array}$ & $\begin{array}{l}\text { Up-regulation } \\
\text { confirmed }\end{array}$ \\
\hline SMN1 & $\begin{array}{c}\text { HPV16 E6 } \\
\text { HPV16 E7 } \\
\text { HPV16 E6 + E7 }\end{array}$ & $\begin{array}{c}0.21 \\
0.48 \\
0.4 \\
\end{array}$ & $\begin{array}{l}0.86 \\
0.72 \\
0.76\end{array}$ & $\begin{array}{c}\text { Down-regulation } \\
\text { confirmed }\end{array}$ \\
\hline HIST2H2AA4 & $\begin{array}{c}\text { HPV16 E6 } \\
\text { HPV16 E7 } \\
\text { HPV16 E6 + E7 }\end{array}$ & $\begin{array}{c}-0.09 \\
-0.06 \\
0.08\end{array}$ & $\begin{array}{l}1.06 \\
1.04 \\
0.95\end{array}$ & $\begin{array}{l}\text { Up-regulation } \\
\text { NOT confirmed }\end{array}$ \\
\hline
\end{tabular}

Differential gene expression found by RNA sequencing are validated in HPV16-transfected JAR cells for the selected genes IFIT1, ISG15, HSPA1B, HIST2H2AA4, SMN1. $\triangle \triangle \mathrm{Ct}$ summarizes Ct values for three transfection experiments and RT-qPCR was run in triplicates. All Ct values were normalized against the reference gene GAPDH.

IFIT1, as well as ISG15, are interferon-induced genes reported to be activated immediately and robustly upon viral infection [21,22]. Both genes have previously been studied in relation to HPV [21,23-25] and IFIT1 was found to directly interact with HPV L1, leading to the translocation of HPV E1 and inhibition of its DNA helicase activity. Therefore, we decided to investigate if HPV presence in the placenta gives rise to an up-regulation of IFIT1 and ISG15 expression in our patient cohort including placental material from spontaneous and elective abortions, as well as from preterm and normal full-term deliveries (Ambühl et al. 2017 [19]). Differential expression of ISG15 and IFIT1 was investigated using TaqMan Gene Expression Assays (for RT-qPCR data see Additional file 3) in 32 HPV-positive and 32 HPV-negative placental samples. The data showed that neither ISG15 nor IFIT1 were upregulated in HPV-positive placenta samples (Table 3), probably illustrating that HPV was not in its active phase of viral infection at the time when samples were collected from patients.

Table 3. Validation in patient samples.

\begin{tabular}{|c|c|c|c|}
\hline Gene ID & $\Delta \Delta \mathrm{Ct}$ & Fold Change $\left(2^{-\Delta \Delta C t}\right)$ & Number of Samples Tested/Included \\
\hline IFIT1 & 0.065 & 0.96 & $\begin{array}{l}\text { 32/16 HPV positives } \\
32 / 14 \mathrm{HPV} \text { negatives }\end{array}$ \\
\hline ISG15 & 0.143 & 0.91 & $\begin{array}{l}\text { 32/18 HPV positives } \\
\text { 32/16 HPV negatives }\end{array}$ \\
\hline
\end{tabular}

Differential expression of IFIT1 and ISG15 was evaluated in placental RNA from 32 HPV-positive and 32 HPV-negative placental samples. Number of samples included refers to samples with valid RT-qPCR results according to standard curves and dynamic range. The fold change for HPV-positive vs. negative placental samples is included. Ct values were normalized against reference genes GAPDH and TBP.

\subsection{HPV16 E6 and E7 are not Transcribed in HPV16-Positive Placenta}

Simple detection of viral DNA by PCR, hybrid capture assay, or other methods is never equal to a causative role in the adverse outcome of pregnancy or diseases in general. Expression of HPV16 E6 and E7 genes in patient placenta were therefore tested by the use of RT-qPCR to document viral activity (for RT-qPCR data see Additional file 4). Table 4 shows data on gene expression for HPV16 E6 and E7 based on analysis of five HPV16-positive and five HPV-negative placentas. The HPV16-positive 
cell line SiHa was used as a positive control. Viral activity could only be confirmed for SiHa cells but not for patients with HPV16-positive placentas (Table 4).

Table 4. Viral activity in placental tissue.

\begin{tabular}{cccc}
\hline Sample & Ct GAPDH & $\Delta$ Ct HPV16 E6 & $\Delta$ Ct HPV16 E7 \\
\hline SiHa & 13.83 & 5.32 & 4.84 \\
HPV+ patient 1 & 16.2 & - & - \\
HPV+ patient 2 & 15.36 & - & - \\
HPV+ patient 3 & 14.92 & - & - \\
HPV+ patient 4 & 17.39 & - & - \\
HPV+ patient 5 & 15.26 & - & - \\
HPV- patient 1 & 16.31 & - & - \\
HPV- patient 2 & 16.61 & - & - \\
HPV- patient 3 & 14.2 & - & - \\
HPV- patient 4 & 14.7 & - & - \\
HPV- patient 5 & 14.86 & - & - \\
\hline
\end{tabular}

Expression of HPV16 E6 and E7 were evaluated in placental RNA from five patients with HPV16-positive and five patients with HPV-negative placentas by RT-qPCR. The HPV16 positive cell line SiHa was used as a positive control. Ct-values for specific PCR products are reported. GAPDH was used as a reference gene.

\section{Discussion}

Trophoblasts have earlier been claimed to constitute the predominant cellular targets of HPV in placenta by in situ PCR or hybridization [10,26,27]. A direct co-localization between HPV and its target cells has however been lacking. Here we show that HPV is clearly co-localized with syncytiotrophoblast cells of human placentas.

Placental HPV infection has been suggested to be linked to spontaneous abortion, spontaneous preterm delivery and placental abnormalities $[3,4,17]$. However, HPV prevalence in pregnant women varies widely and ranges from 0 to $70 \%$ in placental tissue $[18,28]$. Nevertheless, HPV DNA has been co-localized with syncytiotrophoblast cells and therefore potential effects on placental development and consequences for the present pregnancy cannot be excluded. This work aimed therefore at investigating the transcriptome of HPV-transfected trophoblast cells, which allows for an increased insight into the effect on possible deregulation of gene expression. Among others, we identified two up-regulated candidate genes after HPV transfection of trophoblast cells. Both ISG15, an interferon-stimulated gene, and IFIT1, a gene encoding an interferon-induced protein with tetratricopeptide repeats, are described to be involved in the antiviral response via the interferon system [21,22]. The interferon system constitutes a major role in the host's innate immune response to viral infections [29]. Viral stress induces transcription of IFIT1 rapidly and IFIT1 has been described to directly interact with HPV E1 [21]. IFIT1 is reported to translocate E1 from the nucleus to the cytoplasm to inhibit DNA helicase activity of E1 and HPV DNA replication [21]. Contrary to our results, several studies find that HPV down-regulates constitutive expression of interferon-stimulated genes (ISGs) in transcriptome analyses of keratinocytes [23-25]. Thus, the cellular target of HPV infection appears to be important for the induced response. IGS15 is an ubiquitin-like protein conjugating to target proteins in the process of ISGylation impairing viral replication in vivo [30,31]. Furthermore, IGS15 is described to induce production of interferon gamma (IFN $\gamma$ ) from T cells, enhance natural killer cell proliferation, and activate monocytes and macrophages via the induced IFN $\gamma$ [22]. Further investigations are needed to clarify if the immune system of the placenta or the pregnant woman are able to respond to an infection with HPV, thereby possibly preserving the present pregnancy. In addition, others have suggested that the HPV-associated pathological mechanism could include E6 and E7's effects on the immune system [15,32].

Up-regulation of antiviral genes, ISG15 and IFIT1, was not detected in HPV positive placental tissue. Bearing in mind that the nature of in vitro experiments implies boosting of possible downstream effects due to overexpression and investigation of short-term effects, this might not be surprising. 
Moreover, placental samples constitute a snapshot of viral infection and gene expression at the time-point of sample collection. HPV infections may have been present for some time. Both ISG15 and IFIT1 are found to be induced rapidly and robustly after IFN stimulation upon viral infection [21,33]. Therefore, differences in gene expression may be difficult to measure in patient samples and this illustrates that HPV detected in patients was not in its active phase of viral infection. To test this further, we investigated transcription of HPV16 E6 and E7 in patients with HPV16-positive placentas by RT-qPCR. The impact of viral infections is not directly proportional to detection of viral DNA in clinical samples, as viral activity is crucial for a virus to play a causative role in diseases in general. Viral activity in HPV16-positive patients was not detected. Therefore, we suggest that HPV infections in patients may be latent, as viral DNA is present without any evidence of ongoing viral replication. However, effects of HPV DNA on placental cells cannot be excluded and further investigations on the role of placental HPV infections on pregnancy outcome are needed.

\section{Materials and Methods}

\subsection{Placental Material and HPV Screening}

Patient material includes placental tissue from the following four study groups: Women who presented with (A) a spontaneous abortion (between week 8 and 22 of gestation); (B) a spontaneous preterm delivery (before $37+0$ weeks of gestation); (C) an elective abortion (between week 8 and 22 of gestation); and (D) a full-term delivery ( $\geq 37$ weeks of gestation). All women were recruited at the Departments of Obstetrics and Gynecology at Aarhus University Hospital (preterm deliveries and spontaneous abortions), Aalborg University Hospital (spontaneous abortions), and North Denmark Regional Hospital (full-term deliveries and elective abortions) between March 2014 and April 2016. Women below the age of 18 years of age, with a multifetal pregnancy, known chromosomal or fetal abnormalities, gestational diabetes mellitus, and pre-eclampsia/HELLP (Hemolysis, Elevated Liver enzymes, and Low Platelet count) syndrome were excluded.

Placental samples were collected in RNAlater and $4 \%$ formalin immediately after delivery/abortion, or at the latest after four hours, during which the placenta was stored at $4{ }^{\circ} \mathrm{C}$. Samples in formalin were paraffin-embedded and used for histology analyses and in situ hybridization. Placental tissue stored in RNAlater was used for DNA purification using the QIAGEN AllPrep DNA/RNA Mini purification kit (QIAGEN Inc., Valencia, CA, USA) according to the manufacturer's instructions. HPV detection was performed by nested PCR using general MY09/11 [34] and GP5+/6+ [35] primers and is described in more detail in Ambühl et al. 2017 [19]. HPV-positive patients in this study are defined as patients where HPV DNA could be detected in the placenta.

\subsection{Fluorescence in Situ Hybridization (FISH)/Fluorescence Immunohistochemistry (FIHC)}

Placenta samples testing positive for HPV by PCR (Ambühl et al. 2017 [19]) were analyzed with Tyramide Signal Amplification (TSA) FISH in combination with FIHC to co-localize HPV in placental cells. Sections measuring $4 \mu \mathrm{m}$ from formalin-fixed and paraffin-embedded (FFPE) placental samples were used together with the ZytoFast HPV Screening Probe (digoxygenin-labelled) (ZytoVision GmbH, Bremerhaven, Germany), which detects 17 different HPV types (HPV-6, 11, 16, 18, 31, 33, 35, 39, 45, $51,52,56,58,59,66,68$, and 82). Histological slides were deparaffinized in xylene and blocked for endogenous peroxidase activity with $0.7 \% \mathrm{H}_{2} \mathrm{O}_{2}$ for $15 \mathrm{~min}$. Before the hybridization of probes, tissue slides were pretreated by boiling for $10 \mathrm{~min}$ and pepsin digested (ZytoVision $\mathrm{GmbH}$ ) at $37^{\circ} \mathrm{C}$ for $10 \mathrm{~min}$. On all sections $10 \mu \mathrm{L}$ of DNA probes were applied and covered with coverslips. Slides were denaturated at $75^{\circ} \mathrm{C}$ for $5 \mathrm{~min}$ and hybridized at $37^{\circ} \mathrm{C}$ for $1 \mathrm{~h}$. After stringent washing and protein blocking at $4{ }^{\circ} \mathrm{C}$ overnight, probes were visualized using HPR-anti-DIG (PerkinElmer, Waltham, MA, USA) (1:1000) for $30 \mathrm{~min}$, TSA-DIG (PerkinElmer) (1:150) for $5 \mathrm{~min}$, primary antibodies rabbit anti-DIG (1:200, Dako, Carpinteria, CA, USA) and mouse anti-CK7 (1:100, Dako, for trophoblasts) for $30 \mathrm{~min}$, secondary antibodies (Alexa fluor 488 goat anti-rabbit, 1:500 and Alexa fluor 555 goat anti-mouse, 1:200, 
Dako) for 30 min and DAPI (SantaCruz, Rio Grande City, TX, USA). Each experiment was conducted including the following positive and negative controls: an HPV-infected cervical cancer tissue section applying the HPV screening probe plus TSA, a control placenta applying the ZytoFast DNA(+) Control Probe (ZytoVision $\mathrm{GmbH}$ ) with and without TSA, and the same control placenta applying the ZytoFast DNA (-) Control Probe (ZytoVision $\mathrm{GmbH}$ ) plus TSA. The DNA(+) probe detects human Alu repetitive sequences, whereas the DNA(-) probe contains oligonucleotides without known consensus to any naturally occurring sequence.

\subsection{Cell Culture, Transfection and RNA Extraction}

The trophoblast cell line used in this study is JAR (ACC 462, Leibniz-Institut DSMZ GmbH, Braunschweig, Germany). All cells were maintained at $37{ }^{\circ} \mathrm{C} / 5 \% \mathrm{CO}_{2}$. JAR cells were cultured in RPMI media (biowest, France) supplemented with 10\% fetal bovine serum (biowest, Nuaillé, France), and $1 \%$ penicillin/streptomycin (biowest, Nuaillé, France).

JAR cells were transiently transfected in 6-well plates $\left(4 \times 10^{5}\right.$ cells per well) using $1 \mu \mathrm{g}$ DNA and 3:1 FuGENE HD Transfection Reagent (Promega, Madison, WI, USA). The constructs used for transfection were the following: pcDNA3.1_HPV16E6 (insert included sequence of HPV16E6 nt83-nt559 (GenBank K02718.1)) and pcDNA3.1_HPV16E7 (insert included sequence of HPV16E7 nt562-858 (GenBank K02718.1)). Constructs are produced and purchased from GeneArt Gene Synthesis (Invitrogen). Transfection efficiency was assessed by transfecting cells separately with $1 \mu \mathrm{g}$ pEGP and was typically 30\%. Cells were transfected with pcDNA3.1_HPV16E6 and pcDNA3.1_HPV16E7 separately, and were co-transfected. Furthermore, cells were transfected with the empty pcDNA3.1 vector as a control.

Cells were harvested two days post-transfection and dry cell pellets were stored at $-20{ }^{\circ} \mathrm{C}$ until RNA extraction. RNA extraction was done using Trizol reagent (Ambion, Life Technologies, Carlsbad, CA, USA) and the mirVana miRNA Isolation Kit (Ambion, Life Technologies). RNA quality was determined by Agilent Bioanalyzer using the Agilent RNA 6000 Nano Kit (Agilent, Santa Clara, CA, USA) according to the manufacturer's instructions.

\subsection{Quantitative Reverse Transcription PCR}

RT-qPCR was used for confirmation of HPV16 E6 and E7 transcription after transfection of trophoblast cells. Before complementary DNA (cDNA) synthesis, RNA was treated with DNase I (Invitrogen, Waltham, MA, USA). First, strand cDNA was generated by reverse transcription from $2 \mu \mathrm{g}$ of total RNA in a total volume of $20 \mu \mathrm{L}$ using the Affinity Script QPCR cDNA synthesis kit (Agilent, Santa Clara, CA, USA). Quantitative expression of HPV16E6 and HPV16E7 genes was analyzed by real-time PCR using the Stratagene $\mathrm{M} \times 3005 \mathrm{P}$ system and the Brilliant III Ultra-Fast SYBR green QPCR Master Mix (Agilent, Santa Clara, CA, USA). cDNA was diluted 1:1 with $\mathrm{H}_{2} \mathrm{O}$ and used for real-time PCR. cDNA was amplified in a total PCR reaction volume of $20 \mu \mathrm{L}$ with specific primers using the following cycle conditions: $95^{\circ} \mathrm{C}$ for $10 \mathrm{~min}$, followed by 40 cycles of $95{ }^{\circ} \mathrm{C}$ for $30 \mathrm{~s}, 59$ ${ }^{\circ} \mathrm{C}$ for $30 \mathrm{~s}$ and $72{ }^{\circ} \mathrm{C}$ for $30 \mathrm{~s}$. RT-qPCRs were run in triplicates and No template controls as well as a positive control including cDNA from SiHa cells (HPV16 positive) have been included. Gene expression was normalized using values obtained for the reference gene GAPDH $(\triangle \mathrm{Ct}=\mathrm{Ct}$ transfected gene-Ct reference gene). Absolute $\mathrm{Ct}$ values for HPV16 E6 and E7 confirmed expression of HPV16 E6 and E7 after transfection with pcDNA3.1_HPV16E6 and pcDNA3.1_HPV16E7 (for RT-qPCR data see Additional file 1). A dissociation curve was generated after each experiment to confirm amplification of a single PCR product.

In addition, RT-qPCR was performed to analyze HPV16 E6 and E7 transcription in patient material. Patient RNA for RT-qPCR analysis was purified from placenta samples stored in RNAlater using the QIAGEN AllPrep DNA/RNA Mini purification kit (QIAGEN Inc., Valencia, CA, USA) according to the manufacturer's instructions. RNA quality was determined by Agilent Bioanalyzer using the Agilent RNA 6000 Nano Kit (Agilent, Santa Clara, CA, USA) according to the manufacturer's instructions. 
cDNA synthesis, including DNase I treatment, as well as RT-qPCR, was performed as described above with the following differences: Input for cDNA synthesis was $1.5 \mu \mathrm{g}$ of total RNA. RT-qPCRs were run in triplicates and No template controls as well as a positive control including cDNA from SiHa cells (HPV16 positive) have been included. GAPDH was used as a reference gene. A dissociation curve was generated after each experiment to confirm single PCR product amplification and product specificity (Tm GAPDH: $86.6^{\circ} \mathrm{C}$, Tm HPV16 E6: $81^{\circ} \mathrm{C}$, Tm HPV16 E7: $\left.79{ }^{\circ} \mathrm{C}\right)$. Ct-values for specific PCR products are reported (for RT-qPCR data see Additional file 4).

Primers used for amplification were the following:

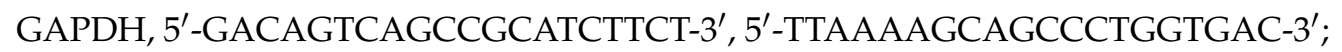
HPV16E6, 5'-CTGCAATGTTTCAGGACCCAC-3' ' 5'-GTTGTTTGCAGCTCTGTGCAT-3'; HPV16E7, 5'-AGAACCGGACAGAGCCCATTA-3', 5'-CGCACAACCGAAGCGTAGA-3'

Validation of candidate genes in HPV transfections of JAR cells and confirmation of in vitro results in patient material (total RNA from placental tissue) were performed by the use of TaqMan Gene Expression Assays (Applied Biosystems) for IFIT1 (Hs03027069_s1; Cat. \# 4331182), ISG15 (Hs01921425_s1; Cat. \# 4331182), HSPA1B (Hs01040501_sH; Cat. \# 4331182), SMN1 (Hs02341953; Cat. \# 4331182) and HIST2H2AA4 (Hs00358508_s1; Cat. \# 4331182). GAPDH (4326317E) and TBP $(4333769 \mathrm{~F})$ were used as endogenous controls. Expression of candidate genes have been validated in three separate transfection experiments and $32 \mathrm{HPV}$-positive as well as $32 \mathrm{HPV}$-negative placental samples. RT-qPCRs were run in triplicates and No template controls as well as -RNA controls have been included. cDNA synthesis was done using the High-capacity RNA-to-cDNA kit (Applied Biosystems, Foster City, CA, USA). For validation in cell lines, an input of $100 \mathrm{ng}$ of cDNA was used. Each of the 20- $\mu \mathrm{L}$ RT-qPCR reactions included $10 \mu \mathrm{L}$ of $2 \times$ TaqMan Gene Expression Master Mix and $1 \mu \mathrm{L}$ of $20 \times$ TaqMan Gene Expression Assay (Applied Biosystems). Cycling conditions were: $50{ }^{\circ} \mathrm{C}$ for $2 \mathrm{~min}, 95^{\circ} \mathrm{C}$ for $10 \mathrm{~min}$, followed by 40 cycles of $95^{\circ} \mathrm{C}$ for $15 \mathrm{~s}$ and $60^{\circ} \mathrm{C}$ for $1 \mathrm{~min}$. A reference RNA consisting of a mix of equal amounts of RNA from four different HPV-negative placenta samples (one from each study group) plus total RNA from JAR cells was used for generation of standard curves and as an inter-plate calibrator. The quantification of transcripts and calculations on differential expression of candidate genes between JAR cells transfected with HPV16 E6 and E7 or pcDNA3.1 empty vector, as well as between patients with HPV-positive and -negative placentas was reported using the 2(- $\Delta \Delta \mathrm{Ct})$ method [36]. The following calculations were performed: $\Delta \Delta \mathrm{Ct}=\Delta \mathrm{Ct} H \mathrm{HV}$ vector- $\Delta \mathrm{Ct}$ empty vector and $\Delta \mathrm{Ct}=\mathrm{Ct}$-transfected gene-Ct reference gene; and $\Delta \Delta \mathrm{Ct}=\Delta \mathrm{Ct}$ HPV-negative patients- $\Delta \mathrm{Ct}$ HPV-positive patients and $\Delta \mathrm{Ct}=\mathrm{Ct}$ gene of interest-Ct reference gene (for RT-qPCR data see Additional files 2 and 3).

\subsection{RNA Sequencing and DEG Analyses}

Total RNA was purified from JAR cells transfected with either: (1) pcDNA3.1_HPV16E6; (2) pcDNA3.1_HPV16E7; (3) pcDNA3.1_HPV16E6 and pcDNA3.1_HPV16E7; or (4) pcDNA3.1 (empty vector). The experiment was performed in triplicates and therefore 12 samples were sent for RNA sequencing at the Beijing Institute of Genomics, Chinese Academy of Sciences (BGI, Beijing, China). Library construction and paired-end transcriptome sequencing (on an Illumina HiSeq 2000/2500 platform, $20 \mathrm{M}$ clean reads/sample, $4 \mathrm{G}$ clean data) as well as bioinformatics were performed by the BGI using the manufacturer's protocol. Short sequencing reads were filtered removing reads with adaptors, reads where unknown bases were more than $5 \%$ and low-quality reads. Genome mapping of clean reads was performed using HISAT (Hierarchical Indexing for Spliced Alignment of Transcripts) [37]. The NOIseq method described by Tarazona et al. [20] was used for detection of differentially expressed genes. Input parameters were the following: fold-change $\geq 2.0$ and probability $\geq 0.8$. Raw data from RNA sequencing can be found in the NCBI Sequence Read Archive (SRA, BioProject number PRJNA386626). 


\subsection{Ethical Approval}

The local ethical committee (Den Videnskabsetiske Komité for Region Nordjylland) approved this research (N-20130082) on 4 February 2014. Additionally, the project has been reported to the Data Protection Agency. All participants gave informed consent.

\section{Conclusions}

This study clearly localized HPV to syncytiotrophoblast cells in placenta. Moreover, the study of molecular effects of HPV transfection of trophoblast cells identified two candidate genes, ISG15 and IFIT1, possibly involved in the antiviral response after interferon induction upon viral infection. Further investigations on the role of placental HPV infections are needed and possible consequences for the developing fetus should be considered.

Supplementary Materials: The following are available online at www.mdpi.com/2076-0817/6/3/40/s1, Additional files 1-4. The RNA sequencing datasets produced and analyzed in this study are available in the NCBI Sequence Read Archive (SRA), https:/ / www.ncbi.nlm.nih.gov/sra. The BioProject number is PRJNA386626.

Acknowledgments: This work is financially supported by Center for Clinical Research, North Denmark Regional Hospital/Department of Clinical Medicine, Aalborg University. Furthermore, the project has received funding from the 'Region Nordjyllands Forskningsfond', 'Marie Pedersen og Jensine Heibergs Legat', 'Aragon fonden', and 'Kong Christian den Tiendes fond' to cover running expenses.

Author Contributions: L.M.M.A. performed the laboratory work, was involved in data analysis, produced figures and tables and was primarily involved in the study design, data interpretation and the writing process. S.S. was involved in study design, presentation and interpretation of data in figures and tables as well in the finalization of the manuscript. A.B.V. optimized the transfection efficiency and was involved in the revision and finalization of the manuscript. U.B. and K.D. were involved in the study design, interpretation of data and finalization of the manuscript.

Conflicts of Interest: The authors declare no conflict of interest.

\section{References}

1. Zur Hausen, H. Papillomaviruses and cancer: From basic studies to clinical application. Nat. Rev. Cancer. 2002, 2, 342-350. [CrossRef] [PubMed]

2. Pfister, H. Biology and biochemistry of papillomaviruses. In Reviews of Physiology, Biochemistry and Pharmacology; Reviews of Physiology, Biochemistry and Pharmacology; Springer: Berlin/Heidelberg, Germany, 1984; Volume 99, pp. 111-181.

3. Hermonat, P.L.; Han, L.; Wendel, P.J.; Quirk, J.G.; Stern, S.; Lowery, C.L.; Rechtin, T.M. Human papillomavirus is more prevalent in first trimester spontaneously aborted products of conception compared to elective specimens. Virus Gen. 1997, 14, 13-17.

4. Gomez, L.M.; Ma, Y.; Ho, C.; McGrath, C.M.; Nelson, D.B.; Parry, S. Placental infection with human papillomavirus is associated with spontaneous preterm delivery. Hum. Reprod. 2008, 23, 709-715. [CrossRef] [PubMed]

5. Worda, C.; Huber, A.; Hudelist, G. Prevalence of cervical and intrauterine human papillomavirus infected in the third trimester in asymptomatic women. J. Soc. Gynecol. Investig. 2005, 12, 5-9. [CrossRef] [PubMed]

6. Armbruster-Moraes, E.; Ioshimoto, L.M.; Leao, E.; Zugaib, M. Detection of human papillomavirus deoxyribonucleic acid sequences in amniotic fluid during different periods of pregnancy. Am. J. Obstet. Gynecol. 1993, 169, 1074. [CrossRef]

7. Burguete, T.; Fontanges-Darriet, M.; Roset, E.; Hager, H.; Ko, A.; Bischof, P. Evidence for infection of the human embryo with adeno-associated virus in pregnancy. Hum. Reprod. 1999, 14, 2396-2401. [CrossRef] [PubMed]

8. Tseng, C.J.; Lin, C.Y.; Wang, R.L.; Chen, L.J.; Chang, Y.L.; Hsieh, T.T.; Pao, C.C. Possible transplacental transmission of human papillomaviruses. Am. J. Obstet. Gynecol. 1992, 166, 35-40. [CrossRef]

9. Wang, X.; Zhu, Q.; Rao, H. Maternal-fetal transmission of human papillomavirus. Chin. Med. J. (Engl.) 1998, 111, 726-727. [PubMed] 
10. Hermonat, P.L.; Kechelava, S.; Lowery, C.L.; Korourian, S. Trophoblasts are the preferential target for human papilloma virus infection in spontaneously aborted products of conception. Hum. Pathol. 1998, 29, 170-174. [CrossRef]

11. Liu, Y.; You, H.; Chiriva-Internati, M.; Korourian, S.; Lowery, C.L.; Carey, M.J.; Smith, C.V.; Hermonat, P.L. Display of complete life cycle of human papillomavirus type 16 in cultured placental trophoblasts. Virology 2001, 290, 99-105. [CrossRef] [PubMed]

12. You, H.; Liu, Y.; Agrawal, N.; Prasad, C.K.; Chiriva-Internati, M.; Lowery, C.L.; Kay, H.H.; Hermonat, P.L. Infection, replication, and cytopathology of human papillomavirus type 31 in trophoblasts. Virology 2003, 316, 281-289. [CrossRef] [PubMed]

13. Stanley, M.A. Epithelial cell responses to infection with human papillomavirus. Clin. Microbiol. Rev. 2012, 25, 215-222. [CrossRef] [PubMed]

14. Ghittoni, R.; Accardi, R.; Hasan, U.; Gheit, T.; Sylla, B.; Tommasino, M. The biological properties of E6 and E7 oncoproteins from human papillomaviruses. Virus Genes. 2010, 40, 1-13. [CrossRef] [PubMed]

15. You, H.; Liu, Y.; Carey, M.J.; Lowery, C.L.; Hermonat, P.L. Defective 3A trophoblast-endometrial cell adhesion and altered 3A growth and survival by human papillomavirus type 16 oncogenes. Mol. Cancer Res. 2002, 1, 25-31. [PubMed]

16. Ambühl, L.M.M.; Baandrup, U.; Dybkær, K.; Blaakær, J.; Uldbjerg, N.; Sørensen, S. Human Papillomavirus Infection as a Possible Cause of Spontaneous Abortion and Spontaneous Preterm Delivery. Infect. Dis. Obstet. Gynecol. 2016, 2016, 1-19. [CrossRef] [PubMed]

17. Zuo, Z.; Goel, S.; Carter, J.E. Association of cervical cytology and HPV DNA status during pregnancy with placental abnormalities and preterm birth. Am. J. Clin. Pathol. 2011, 136, 260-265. [CrossRef] [PubMed]

18. Sifakis, S.; Ergazaki, M.; Sourvinos, G.; Koffa, M.; Koumantakis, E.; Spandidos, D. Evaluation of Parvo B19, CMV and HPV viruses in human aborted material using the polymerase chain reaction technique. Eur. J. Obstet. Gynecol. Reprod. Biol. 1998, 76, 169-173. [CrossRef]

19. Ambühl, L.M.M.; Leonhard, A.K.; Zakhary, C.W.; Jørgensen, A.; Blaakær, J.; Dybkær, K.; Baandrup, U.; Uldbjerg, N.; Sørensen, S. Human Papillomavirus infects placental trophoblast and Hofbauer cells, but appears not to play a causal role in miscarriage and preterm labor. Acta Obstet. Gynecol. Scand. 2017, in press.

20. Tarazona, S.; Garcia-Alcalde, F.; Dopazo, J.; Ferrer, A.; Conesa, A. Differential expression in RNA-seq: A matter of depth. Genome Res. 2011, 21, 2213-2223. [CrossRef] [PubMed]

21. Terenzi, F.; Saikia, P.; Sen, G.C. Interferon-inducible protein, P56, inhibits HPV DNA replication by binding to the viral protein E1. EMBO J. 2008, 27, 3311-3321. [CrossRef] [PubMed]

22. Jeon, Y.J.; Yoo, H.M.; Chung, C.H. ISG15 and immune diseases. Biochim. Biophys. Acta 2010, 1802, 485-496. [CrossRef] [PubMed]

23. Chang, Y.E.; Laimins, L.A. Microarray analysis identifies interferon-inducible genes and Stat-1 as major transcriptional targets of human papillomavirus type 31. J. Virol. 2000, 74, 4174-4182. [CrossRef] [PubMed]

24. Karstensen, B.; Poppelreuther, S.; Bonin, M.; Walter, M.; Iftner, T.; Stubenrauch, F. Gene expression profiles reveal an upregulation of E2F and downregulation of interferon targets by HPV18 but no changes between keratinocytes with integrated or episomal viral genomes. Virology 2006, 353, 200-209. [CrossRef] [PubMed]

25. Nees, M.; Geoghegan, J.M.; Hyman, T.; Frank, S.; Miller, L.; Woodworth, C.D. Papillomavirus type 16 oncogenes downregulate expression of interferon-responsive genes and upregulate proliferation-associated and NF-kappaB-responsive genes in cervical keratinocytes. J. Virol. 2001, 75, 4283-4296. [CrossRef] [PubMed]

26. Sarkola, M.E.; Grénman, S.E.; Rintala, M.M.; Syrjänen, K.J.; Syrjänen, S.M. Human papillomavirus in the placenta and umbilical cord blood. Acta Obstet. Gynecol. Scand. 2008, 87, 1181-1188. [CrossRef] [PubMed]

27. Slatter, T.L.; Hung, N.G.; Clow, W.M.; Royds, J.A.; Devenish, C.J.; Hung, N.A. A clinicopathological study of episomal papillomavirus infection of the human placenta and pregnancy complications. Mod. Pathol. 2015, 28, 1369-1382. [CrossRef] [PubMed]

28. Malhomme, O.; Dutheil, N.; Rabreau, M.; Armbruster-Moraes, E.; Schlehofer, R.; Dupressoir, T. Human genital tissues containing DNA of adeno-associated virus lack DNA sequences of the helper viruses adenovirus, herpes simplex virus or cytomegalovirus but frequently contain human papillomavirus DNA. J. Gen. Virol. 1997, 78, 1957-1962. [CrossRef] [PubMed]

29. Fensterl, V.; Sen, G.C. Interferons and viral infections. BioFactors 2009, 35, 14-20. [CrossRef] [PubMed] 
30. Lai, C.; Struckhoff, J.J.; Schneider, J.; Martinez-Sobrido, L.; Wolff, T.; García-Sastre, A.; Zhang, D.E.; Lenschow, D.J. Mice lacking the ISG15 E1 enzyme UbE1L demonstrate increased susceptibility to both mouse-adapted and non-mouse-adapted influenza B virus infection. J. Virol. 2009, 83, 1147-1151. [CrossRef] [PubMed]

31. Lenschow, D.J.; Lai, C.; Frias-Staheli, N.; Giannakopoulos N, V.; Lutz, A.; Wolff, T.; Osiak, A.; Levine, B.; Schmidt, R.E.; García-Sastre, A.; et al. IFN-stimulated gene 15 functions as a critical antiviral molecule against influenza, herpes, and Sindbis viruses. Proc. Natl. Acad. Sci. USA 2007, 104, 1371-1376. [CrossRef] [PubMed]

32. Cross, J.C.; Werb, Z.; Fisher, S.J. Implantation and the placenta: Key pieces of the development puzzle. Science 1994, 266, 1508-1518. [CrossRef] [PubMed]

33. Morales, D.J.; Lenschow, D.J. The Antiviral Activities of ISG15. J. Mol. Biol. 2013, 425, 4995-5008. [CrossRef] [PubMed]

34. Manos, M.M.; Ting, Y.; Wright, D.K.; Lewis, A.J.; Broker, T.R.; Wolinsky, S.M. Use of polymerase chain reaction amplification for the detection of genital human papillomavirus. In Molecular Diagnostics of Human Cancer (Cancer Cells); Cold Spring Harbor Laboratory Press: New York, NY, USA, 1989; Volume 7, pp. $209-214$.

35. De Roda Husman, A.M.; Walboomers, J.M.M.; Van den Brule, A.J.C.; Meijer, C.J.L.M.; Snijders, P.J.F. The use of general primers GP5 and GP6 elongated at their 3' ends with adjacent highly conserved sequences improves human papillomavirus detection by PCR. J. Gen. Virol. 1995, 76, 1057-1062. [CrossRef] [PubMed]

36. Livak, K.J.; Schmittgen, T.D. Analysis of relative gene expression data using real-time quantitative PCR and the $2^{-\Delta \Delta C_{\mathrm{T}}}$ Method. Methods 2001, 25, 402-408. [CrossRef] [PubMed]

37. Kim, D.; Langmead, B.; Salzberg, S.L. HISAT: A fast spliced aligner with low memory requirements. Nat. Methods 2015, 12, 357-360. [CrossRef] [PubMed]

(C) 2017 by the authors. Licensee MDPI, Basel, Switzerland. This article is an open access article distributed under the terms and conditions of the Creative Commons Attribution (CC BY) license (http://creativecommons.org/licenses/by/4.0/). 